\title{
SUPERAÇÃO DE DORMÊNCIA DE FLAMBOYANT (Delonix regia) E TREMA (Trema micrantha)
}

\author{
Jean Marlon Freitag Kramer* \\ Patricia da Costa Zonetti**
}

RESUMO: A dormência é caracterizada como a incapacidade de germinação de sementes mesmo quando em condições favoráveis e é considerada uma estratégia evolutiva encontrada em várias espécies. Com o objetivo de investigar métodos de quebra de dormência das espécies Flamboyant (Delonix regia) e Trema (Trema micrantha), foram testados tratamento em banho-maria em diferentes tempos nas sementes de Flamboaynt e tratamento com ácido sulfúrico em diferentes tempos nas sementes de Trema. Após o tratamento, as sementes foram colocadas em caixa gerbox e levadas a uma estufa incubadora refrigerada do tipo BOD a $25^{\circ} \mathrm{C}$ com fotoperíodo de 12 horas. A avaliação do experimento foi realizada a cada oito dias. Para o Flamboyant, os melhores resultados foram observados com o tempo de permanência de 10 e 20 minutos no banho-maria. Já para a Trema, o melhor resultado foi observado com o tempo de exposição de 40 minutos no ácido sulfúrico. Frente a isso, ambas as técnicas empregadas para superação de dormência nas duas espécies mostraram-se eficientes e complementaram dados encontrados em literaturas, podendo conduzir a estratégias mais eficazes para germinação, superação de dormência e manejo das espécies analisadas.

PALAVRAS-CHAVE: Dormência de sementes; Escarificação química; Germinação.

\section{OVERCOMING OF DORMANCY OF THE FLAMBOYANT (Delonix regia) AND WHITE CAPULIN (Trema micrantba)}

ABSTRACT: Dormancy is characterized as the inability of seed germination even under favorable conditions. It is an evolution strategy in several species. Warm-bath treatments were tested at different times with Flamboyant seeds and treatments with sulfuric acid at different times in white capulin seeds were tested so that the break of dormancy of species Flamboyant (Delonix regia) and white capulin (Trema micrantha) could be investigated. After treatment, seeds were placed in a gerbox and

Discente do Curso de Ciências Biológicas da Universidade Federal do Paraná (UFPR), Setor Palotina, Brasil.

** Docente do Departamento de Ciências Agronômicas (DCA) da Universidade Federal do Paraná (UFPR), Setor Palotina, Brasil. E-mail: patricia.zonetti@gmail.com 
taken to a BOD-type refrigerated buffer at $25^{\circ} \mathrm{C}$ and 12 -h photoperiod. Experiment was evaluated every eight days. Best results for the flamboyant were reported for permanence time between 10 and $20 \mathrm{~min}$ in the warm bath. In the case of the white capulin, best results occurred at 40-min exposure time in sulfuric acid. The two techniques for the overcoming of dormancy proved to be efficient and complemented data in the literature, and revealed more efficient strategies for germination, overcoming of dormancy and management of the species under analysis.

KEY WORDS: Seed Dormancy; Chemical Scarification; Germination.

\section{INTRODUÇÃO}

A dormência é uma estratégia evolutiva das espécies para garantir que as sementes encontrem condições ambientais favoráveis para desenvolver plantas adultas, bloqueando a germinação em condições favoráveis imediatas, protegendo as sementes da deterioração, sendo superada ao longo do tempo e em condições naturais de clima ou de alterações climáticas (BIANCHETTI, 1989). Conforme Vieira e Fernandes (1997), a dormência é caracterizada pela incapacidade de germinação de sementes mesmo quando expostas a condições ambientais favoráveis tanto de luz, bem como umidade, oxigênio e temperatura.

A dormência impede a germinação, mas é uma adaptação para a sobrevivência das espécies em longo prazo, pois geralmente faz com que as sementes mantenham-se viáveis por mais tempo, sendo quebrada em situações especiais (KRAMER; KOSLOWSKI, 1972).

A dormência de sementes representa um eficaz recurso para o desenvolvimento das espécies, conferindo à semente resistência às condições desfavoráveis do ambiente e distribuindo a germinação no tempo (BRANCALION et al., 2011). Porém, geralmente, é uma característica indesejável para os viveiristas, porque geram problemas na produção de mudas, além de maior tempo de exposição às condições adversas, como a ação de insetos e doenças, e maior risco de perda de sementes por deterioração (AZEREDO et al., 2010).

Segundo Taiz et al. (2017), em algumas espécies a dormência pode ser imposta ao embrião pelos tecidos circundantes, como o endosperma, pericarpo ou até 
mesmo órgãos extraflorais, como é o caso da dormência imposta pela casca. Nestas sementes os embriões germinam assim que a casca da semente ou outros tecidos circundantes tenham sido danificados ou removidos, como é o caso do Flamboyant.

Taiz et al. (2017) afirmam que a dormência de sementes pode ser quebrada por vários compostos químicos. Dessa forma, numerosas moléculas, como inibidores respiratórios, compostos sulfídricos, oxidantes e compostos nitrogenados têm sido relatadas por quebrar a dormência em determinadas espécies.

Delonix regia, popularmente conhecida como Flamboyant, é uma planta de porte arbóreo originária de Madagascar, Costa Leste da África e Ilhas do Oceano Índico (FLORA DO BRASIL, 2020). É uma espécie ornamental exótica introduzida no Brasil, principalmente para ser utilizada na arborização urbana, tendo se adaptado muito bem às condições de clima tropical e ao tipo do solo brasileiro (ARAÚJO et al., 2009). O período de floração do Flamboyant ocorre entre setembro a dezembro e a frutificação de janeiro a março (LORENZI, 2003).

O Flamboyant apresenta porte médio, podendo chegar até 15 metros de altura. Suas características do formato da copa favorecem o plantio para ornamentação e arborização de ruas, praças e parques, pois além de apresentar uma floração atrativa, propicia sombreamento, auxiliando na melhoria do conforto térmico do microclima, tornando o ambiente mais confortável (AYRES, 2010). Segundo Vieira e Fernades (1997), as sementes do Flamboyant apresentam dormência causada pela impermeabilidade do tegumento, fenômeno natural muito comum entre espécies da família Fabaceae. De acordo com Lorenzi et al. (2003), a escarificação mecânica é um dos métodos indicados para a quebra de dormência do Flamboyant, porém não menciona a porcentagem de germinação obtida. A imersão em água à temperatura de $100^{\circ} \mathrm{C}$ também é um método recomendado e empregado na quebra de dormência desta espécie (MARTINS et al., 2004).

Trema micrantha, conhecida popularmente como Grandiúva ou Trema, pertence à família Cannabaceae que, de acordo com Souza e Lorenzi (2005), possuí distribuição cosmopolita, incluindo 11 gêneros e cerca de 170 espécies. É considerada uma espécie arbórea semicaducifólia e pode atingir até 15 metros de altura. Apresenta ampla presença no território brasileiro, ocorrendo desde a região amazônica até o Estado do Rio Grande do Sul (FLORA DO BRASIL, 2020). A sua floração 
ocorre de outubro a janeiro e os frutos são formados entre março a maio. Os frutos possuem forma globosa, são verde-escuros em fase inicial de maturação e vermelhos quando maduros (LORENZI, 1992).

Conforme Carvalho (1994), os frutos da Trema devem ser colhidos maduros e deixados dois dias em água à temperatura ambiente. Após esta fase, realiza-se a maceração em peneira, acompanhado por lavagem em água corrente, para remoção da polpa e separação das sementes, que devem ser colocadas em ambiente ventilado para secagem. Essa técnica facilita a obtenção da semente.

Na natureza, a ação do fogo ou da luz do Sol nas sementes depositadas no solo (banco de sementes) é suficiente para a quebra da dormência de Trema micrantha. Para produção de mudas, recomenda-se a realização da escarificação química em ácido sulfúrico (90\%) por 10 a 30 minutos (CARVALHO, 1994).

A Trema é uma espécie heliófila, não tolerando sombreamento. Apresenta crescimento rápido e proporciona boa sombra, sendo indicada em plantio misto com espécies oportunistas e tolerantes, em sistemas agroflorestais, bem como para recuperação de ecossistemas degradados (CARVALHO, 1994). Vale ressaltar que esta espécie apresenta grande versatilidade ecológica, sendo uma das plantas pioneiras mais utilizadas em reflorestamentos, na recuperação e na recomposição de áreas degradadas, e é também recomendada para restauração de mata ciliar em locais sem inundação, para conservação de solos, para recuperação de áreas erodidas, entre outros (CARVALHO 2003).

De acordo com Dutra et al. (2013), a crescente expansão dos projetos de restauração florestal tem aumentado a busca por espécies nativas, tornando-se cada vez mais necessários estudos que visem à produção de mudas com menores custos e com maior qualidade. É importante mencionar que a dormência das sementes é um fator que exerce forte influência no desenvolvimento de mudas, durante a fase de viveiro, sendo importante a quebra de dormência em plantas visando à produção de mudas.

O objetivo deste trabalho foi avaliar o efeito do período de permanência no banho-maria para superação de dormência em Delonix regia e o efeito do ácido sulfúrico para superação de dormência em Trema micrantha. 


\section{MATERIAL E MÉTODOS}

As sementes foram coletadas no fragmento da Universidade Federal do Paraná, setor Palotina, localizada no munícipio de Palotina, oeste do Paraná. A vegetação da localidade é a Floresta Estacional Semidecidual (FES), pertencente ao bioma Mata Atlântica.

As coletas das sementes foram realizadas no começo do mês de abril de 2017. As sementes do Flamboyant foram coletadas do solo e as da Trema diretamente da árvore, com o auxílio do podão para o corte do ramo contendo os frutos maduros.

Após as coletas, as sementes foram armazenadas no Laboratório de Fisiologia e Nutrição de Plantas da própria Universidade. As sementes do Flamboyant ficaram armazenadas em temperatura ambiente e os frutos da Trema foram deixados em água à temperatura ambiente por dois dias de modo a facilitar a obtenção da semente.

Em seguida, a Trema foi exposta ao ácido sulfúrico (90\%) durante 10, 20, 30,40 e 50 minutos e o Flamboyant foi exposto ao banho-maria $\left(95^{\circ} \mathrm{C}\right)$ durante 10 , 20, 30, 40 e 50 minutos. Para ambas as espécies, foi deixada uma amostra controle, e as sementes permaneceram intactas sem nenhum tratamento, seguidas por cinco amostras representando os cinco diferentes tempos de exposição para cada tratamento. Cada tratamento foi submetido a quatro repetições.

Posteriormente, as sementes foram distribuídas dentro de uma caixa de plástico do tipo gerbox sobre duas folhas de papel germitest, umedecidas com quantidade de água destilada equivalente a 2,5 vezes a massa do papel não hidratado. Quando necessário, mais água era adicionada ao longo do experimento para hidratar as sementes.

Para a Trema foram colocadas 15 sementes em cada gerbox e para o Flamboyant, dez sementes. As gerbox foram colocadas em uma estufa incubadora refrigerada do tipo BOD com temperatura de $25^{\circ} \mathrm{C}$ e fotoperíodo de 12 horas.

A avaliação da germinação foi realizada pela contagem do número de sementes germinadas seguida por sua retirada, realizada a cada oito dias, considerando-a germinada a partir do aparecimento da radícula. Para o Flamboyant, a avaliação ocorreu em oito e 16 dias. Já para a Trema, a avaliação foi feita em oito, 16, 24, 32 e 40 dias.

De modo a analisar a germinação em cada tratamento foi empregado o teste de Friedman, sendo este uma análise de variância para dados não paramétricos 
(SIEGEL, 1975). O teste foi executado no programa BioEstat, versão 5.3 (AYRES et al., 2007).

\section{RESULTADOS E DISCUSSÃO}

Para o Flamboyant, os tratamentos que apresentaram maior número de sementes germinadas foram os tratamentos 2 e 3; estes referentes ao tempo de 10 e 20 minutos de permanência no banho-maria, respectivamente. Estes resultados já foram observados nos oito primeiros dias.

Por meio do teste de Friedman, verificou-se que há diferenças significativas na germinação do Flamboyant entre os diferentes tempos de exposição ao banho -maria, com um $p=0,01$. A Figura 1 ilustra a diferença na germinação entre os tratamentos. Dessa forma, foi constatado que o tempo de exposição ao banho-maria de 10 minutos (T2) apresentou 55,73\% das sementes totais de Flamboyant germinadas, seguido por T3 (20 minutos) com 42,62\% (Figura 1).

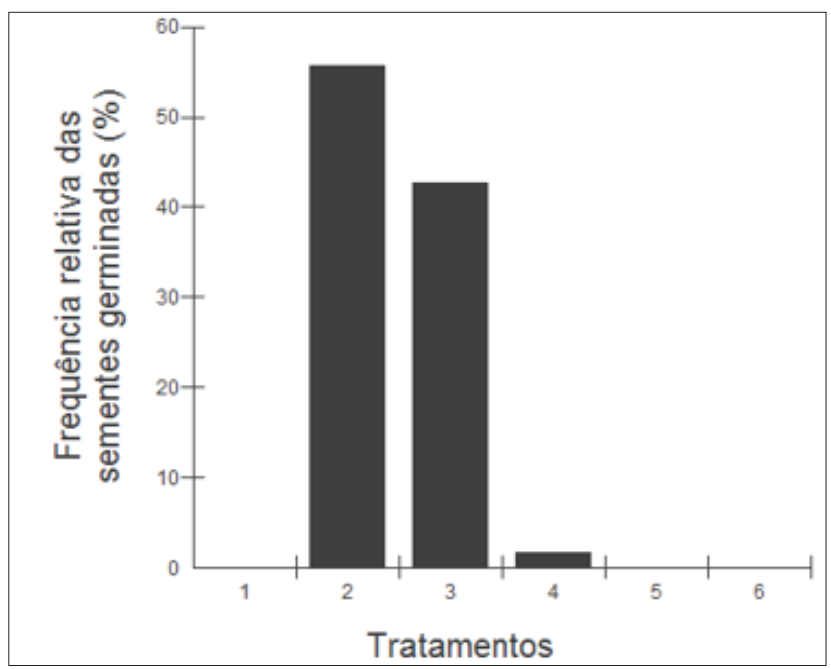

Tratamentos: 1-controle; 2-tempo de exposição de 10 minutos; 3-tempo de exposição de 20 minutos; 4-tempo de exposição de 30 minutos; 5-tempo de exposição de 40 minutos e 6-tempo de exposição de 50 minutos.

Figura 1. Gráfico de colunas referente à frequência relativa das sementes de Flamboyant germinadas em cada tratamento durante 08 dias 
Lorenzi et al. (2003) afirmam que a escarificação mecânica é um dos métodos mais eficientes para quebra de dormência do Flamboyant, pois aceleram a embebição de água pela semente. Tal técnica é frequentemente utilizada nas aulas práticas da disciplina de fisiologia vegetal, na Universidade Federal do Paraná, setor Palotina, sendo bem difundida e com bons resultados. Porém, pouco se sabe em relação à imersão em água fervente $\left(95^{\circ} \mathrm{C}\right)$ durante diferentes tempos. Neste estudo, as sementes de Flamboyant que permaneceram por 10 e 20 minutos em banho-maria apresentaram maior taxa germinativa, como mencionado acima. Destaca-se que os tempos de 40 e 50 minutos não apresentaram nenhuma semente germinada. Acredita-se que esses tempos provocaram danos às sementes, eliminando com isso o seu potencial germinativo.

No estudo de Lopez et al. (2004), foi observado que sementes de Adesmia lantifolia, submetidas ao alagamento por diferentes períodos, apresentaram queda na germinação com o aumento do período de alagamento, sendo que o período de 08 horas de alagamento provocou danos irreversíveis para a semente. Tal relação é semelhante à encontrada neste estudo com o Flamboyant, em que houve queda na germinação com o aumento do período de exposição à água, no entanto, as mesmas se encontravam em alta temperatura. A água fervente tem demonstrado, em alguns estudos, resultados germinativos inferiores e inibidores de germinação, especialmente se submetido por longos períodos (MAEDA; LAGO, 1986; RODRIGUES et al., 1990; BRUNO et al., 2001), ocasionado, provavelmente, pelo comprometimento dos mecanismos fisiológicos das sementes, causando possíveis danos ao embrião.

As sementes de Flamboyant apresentaram germinação rápida, sendo que os resultados dos testes já foram observados nos primeiros oito dias, não havendo avaliações do experimento posterior a 16 dias. Tal fato se deve às características da espécie em si, conforme será discutido em seguida.

Já para a espécie Trema, houve diferenças nas germinações entre os dias, sendo que em oito dias o número de sementes germinadas foi menor do que nas avaliações seguintes. Os tratamentos 4 e 5 foram os que apresentaram os melhores resultados considerando todos os dias de avaliação do experimento.

Em oito dias, os tratamentos que apresentaram os melhores resultados foram T4 (30 minutos) e T5 (40 minutos), ambos com Frequência Relativa (FR) de $31,25 \%$. Verificou-se que não há diferenças significativas na germinação da Trema 
entre os tempos de exposição ao ácido sulfúrico nesta avaliação, apresentando um $\mathrm{p}=0,26$.

Em 16 dias, destacaram-se os tratamentos T5 (40 minutos) e o T6 (50 minutos) exibindo assim os melhores resultados, com $35 \%$ e $25 \%$ das sementes totais de Trema germinadas. Vale ressaltar que as sementes deixadas no controle também germinaram. Nesta avaliação, o valor de p se equivale a 0,06 .

Em 24 dias, T2, T4, T5 e T6 apresentaram novas germinações em relação à avaliação anterior ( 16 dias), com $\mathrm{T} 5$ se destacando como o tratamento com o maior número de sementes germinadas e com maior frequência. Nesta avaliação, houve diferenças significativas entre a germinação de sementes e os tratamentos, apresentando um $\mathrm{p}=0,04$.

Já em 32 dias, somente T2 e T4 apresentaram novas germinações em comparação com a avaliação anterior (24 dias), novamente com T5 se destacando como o melhor tratamento. Nesta avaliação, o número de sementes germinadas em T2, T4 e T6 se igualaram, com FR de 20,75\%. Houve diferenças significativas entre os números de sementes germinadas e os tratamentos, com $\mathrm{p}=0,05$.

Vale salientar que o número de sementes germinadas em 40 dias foi o mesmo que em 32 dias, portanto os valores totais e parciais se igualam nestas duas avaliações. Os gráficos de coluna abaixo ilustram essa diferença na germinação de Trema micrantha entre os diferentes tempos e entre os dias (Figuras 2 e 3).

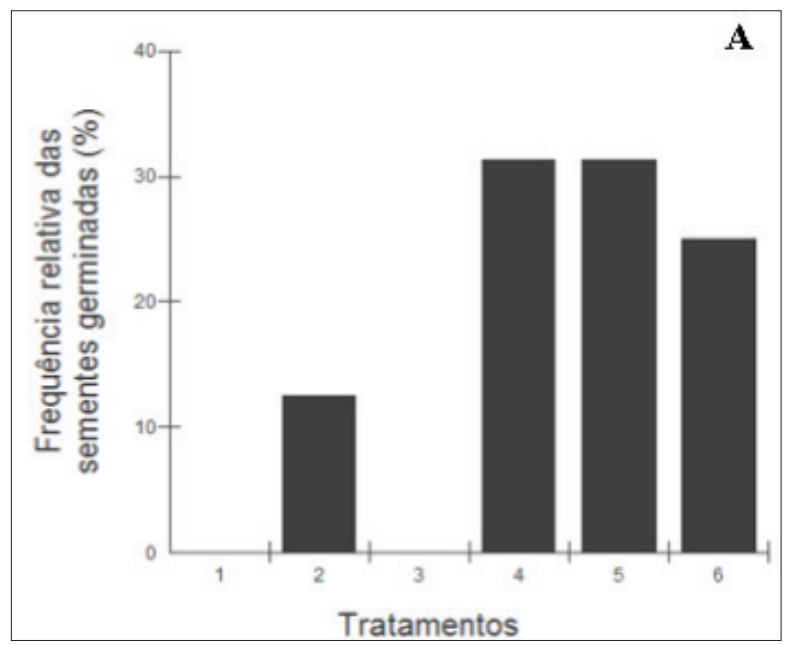




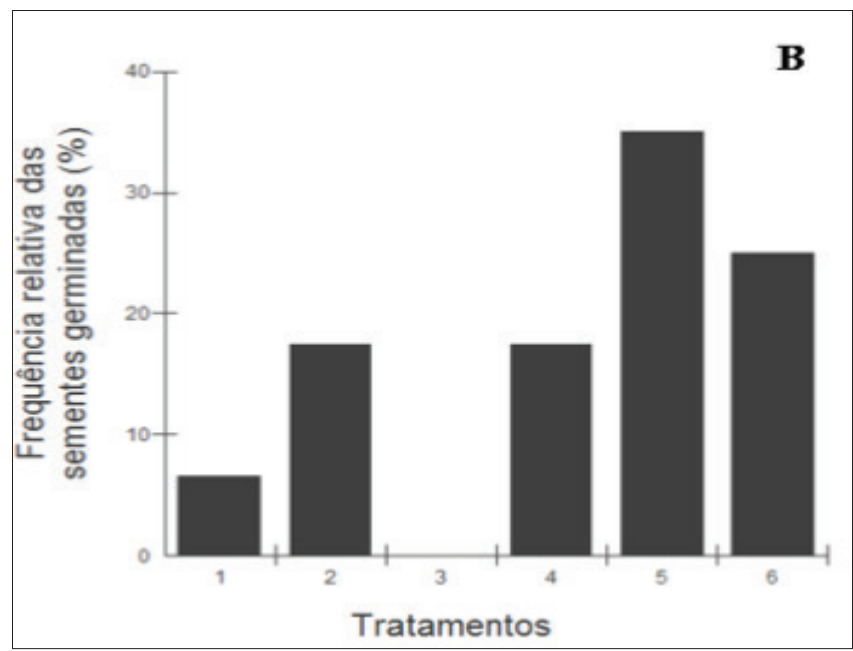

Tratamentos: 1-controle; 2-tempo de exposição de 10 minutos; 3-tempo de exposição de 20 minutos; 4-tempo de exposição de 30 minutos; 5-tempo de exposição de 40 minutos e 6-tempo de exposição de 50 minutos.

Figura 2. Gráfico de colunas referentes às frequências relativas das sementes de Trema germinadas em cada tratamento durante 8 (A) e 16 dias (B)

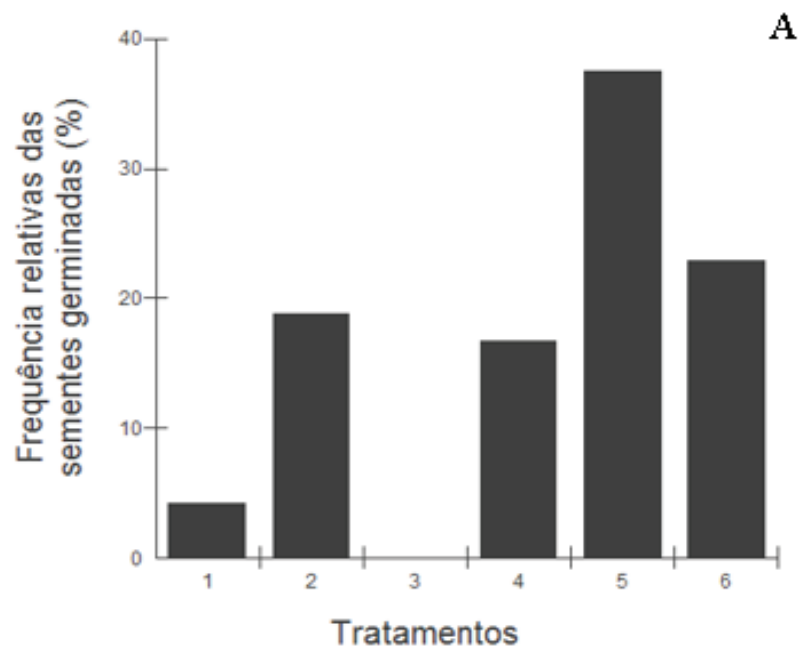




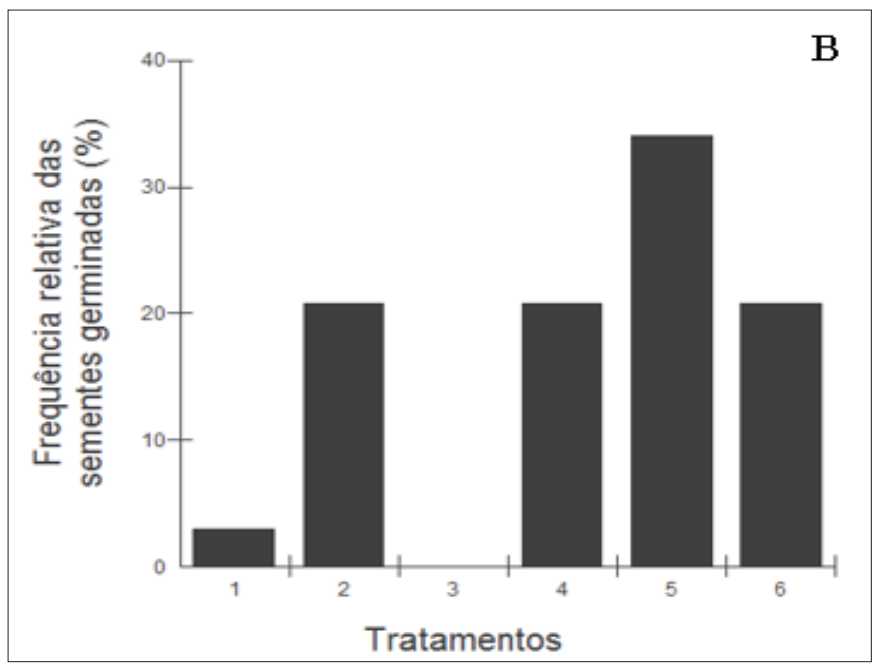

Tratamentos: 1-controle; 2-tempo de exposição de 10 minutos; 3-tempo de exposição de 20 minutos; 4-tempo de exposição de 30 minutos; 5-tempo de exposição de 40 minutos e 6-tempo de exposição de 50 minutos.

Figura 3. Gráfico de colunas referentes às frequências relativas das sementes de Trema germinadas em cada tratamento durante 24 e 32 dias

Para a Trema, os melhores resultados foram obtidos com o tempo de exposição ao ácido sulfúrico durante 40 minutos. É importante mencionar que em 32 dias os números de sementes germinadas durante 10, 30 e 50 minutos foram o mesmo, porém inicialmente não foi isso que se observou. O tempo de exposição de 20 minutos não teve nenhuma semente germinada em nenhum dia de avaliação do experimento.

Os resultados se diferenciaram entre os dias de avaliação do experimento, sendo que no final, em 32 dias, o tratamento que apresentou o melhor resultado foi o tempo de exposição de 40 minutos. Menciona-se que o tempo de exposição de 20 minutos não apresentou nenhuma semente germinada. Estudos direcionados são necessários para verificar esse perfil.

Sobre a Trema, o controle também apresentou germinação, sendo assim, apenas deixar os frutos em água à temperatura ambiente por 48 horas já é um fator para facilitar a embebição de água na semente e consequentemente facilitar sua germinação, conforme descrito por Carvalho (1994). Os resultados deste estudo contribuíram para o trabalho de Carvalho (1994), em que o autor recomenda que a 
escarificação química com ácido sulfúrico para esta espécie seja entre 10 a 30 minutos, porém neste estudo os valores variam até 50 minutos, sendo que o tempo ideal exibindo os melhores resultados é de 40 minutos.

Acredita-se que o embrião de Trema micrantha seja imaturo logo quando removido da planta-mãe, por isso as sementes foram deixadas na água por dois dias. Conforme Taiz et al. (2017), dormência embrionária é quando as sementes não conseguem germinar porque os embriões não atingiram sua maturidade completa. Sendo assim, esses embriões requerem um período adicional para crescer em condições apropriadas antes que possam emergir da semente. Dessa forma, o embrião necessita embeber água para assim ganhar condições para se desenvolver.

Em estudo realizado por Homrichhausen et al. (2003), citado por Taiz et al. (2017), os autores analisaram a embebição de água por sementes de cenoura durante 12, 18, 30 e 40 horas, observando que, conforme maior o tempo de embebição, maior a taxa de germinação das sementes. Deste modo, os melhores resultados para as sementes de cenoura foram obtidos com 40 horas de embebição, e no caso do presente estudo em relação a Trema, com 48 horas.

Este estudo reforçou a recomendação feita por Silva et al. (1993) no sentido de realizar o despolpamento para espécies que produzem frutos carnosos, como é o caso de Trema micrantha. No trabalho realizado por Castellani e Aguiar (1998), onde os autores avaliaram condições preliminares para germinação da Trema, o despolpamento resultou em maior porcentagem e velocidade de germinação, possibilitando maior número de resultados em menor espaço de tempo.

Ainda sobre a Trema, Lorenzi (1992), Seghese et al. (1992) e Castellani e Aguiar (1998) destacam que a germinação desta espécie é apenas moderada, com porcentagem de germinação que varia entre 30 a 34\%. Lorenzi (1992) afirma que para fins de produção de mudas, os frutos devem ser colocados para germinar sem nenhum tratamento. Já por outro lado, Davide et al. (1993) apontam vantagens na germinação desta espécie quando realizada a escarificação química com ácido sulfúrico. Sendo assim, verificou-se maior eficiência na germinação quando os frutos são tratados com ácido sulfúrico, apresentando percentuais de germinação maiores do que as sementes sem nenhum tratamento.

As sementes de Trema apresentam germinação mais lenta do que as semen- 
tes de Flamboyant, sendo que a diferença entre os números de sementes germinadas entre oito e 32 dias foi grande. Possivelmente, esta diferença na velocidade de germinação pode estar ligada à origem das duas espécies, sendo que o Flamboyant é uma espécie exótica e a Trema uma espécie nativa. Conforme Ziller (2001), espécies exóticas normalmente se encontram livres de predadores e parasitas de seus locais de origem, o que atribui a elas vantagens competitivas sobre as espécies nativas.

Vale lembrar que muitas das espécies vegetais exóticas utilizadas na ornamentação vêm-se tornando invasoras nos locais onde foram introduzidas (WEBSTER et al., 2005), adaptando-se com facilidade a ambientes similares aos encontrados em sua região de origem (ZILLER, 2001).

Além do conhecimento da germinação, seriam necessários estudos sobre o desenvolvimento da espécie, já que, segundo Ziller (2001), muitas espécies invasoras possuem características morfológicas e fisiológicas de plantas de início de sucessão que conferem altas taxas de crescimento e utilização de recursos.

De modo a concluir este estudo, podemos afirmar que as sementes de Flamboyant em banho-maria em tempos superiores a 30 minutos têm sua germinação inibida. Em tempos menores, 10 e 20 minutos, a metodologia empregada neste estudo pode ser considerada uma técnica eficiente para superação de dormência nesta espécie, mostrando bons resultados. Já em relação a Trema, a escarificação química com ácido sulfúrico se mostrou bem eficiente para superação de dormência, mostrando também bons resultados, especialmente com o tempo de exposição de 40 minutos.

\section{CONCLUSÃO}

As sementes de Flamboyant tiveram a dormência superadas nos tempos de permanência de 10 e 20 minutos no banho-maria.

Já as sementes de Trema tiveram a dormência superada no tempo de exposição de 10, 30, 40 e 50 minutos no ácido sulfúrico, sendo que o tempo de $40 \mathrm{mi}$ nutos apresentou os melhores resultados. Necessitaram também de maior período em exposição ao tratamento para germinação das sementes se comparadas com as 
sementes de Flamboyant.

Os resultados obtidos neste estudo complementaram dados encontrados em literaturas e podem conduzir a estratégias mais eficazes para germinação, superação de dormência e manejo das espécies analisadas.

\section{REFERÊNCIAS}

ARAÚJO, E. R.; FRANÇA, P. R. C; RODRIGUES, R. S.; OLIVEIRA, L. S. B.; ANDRADE, L. A. Desenvolvimento de mudas de Delonix regia Raf. em diferentes tipos de substratos e recipientes. In: VI CONGRESSO DE MEIO AMBIENTE DA AUGM. São Paulo, out. 2009. Anais... São Paulo, AUGM, 2009.

AYRES, M. C. R. Avaliação do sombreamento natural do flamboyant (Delonix regia) na temperatura de um ambiente. Revista Agrarian, v.3, n.9, p. 200-208, 2010.

AYRES, M.; AYRES Jr, M.; AYRES, D. L.; SANTOS, A. A. S. Bioestat 5.0 aplicações estatísticas nas áreas das ciências biológicase médicas. Belém: IDSM, p. 364, 2007.

AZEREDO, G. A.; PAULA, R. C.; VALERI, S. V.; MORO, F. L. Superação de dormência de sementes de (Piptadenia moniliformis Benth). Revista Brasileira de Sementes, v. 32, p. 49-58, 2010.

BRANCALION P. H. S.; MONDO, V. H. V.; NOVEMBRE A. D. L. C. Escarificação química para a superação da dormência de sementes de saguaraji-vermelho (Colubrina glandulosa Perk. - Rhamnaceae). Revista Árvore, v. 35, p. 119-124, 2011.

BRUNO, R. L. A.; ALVES, E. U.; OLIVEIRA, A. P.; PAULA, R. C. Tratamentos prégerminativos para superar a dormência de sementes de Mimosa caesalpiniaefolia Benth. Revista Brasileira de Sementes, v. 23, n. 2, p. 136-143, 2001.

CARVALHO, P. E. R. Espécies arbóreas brasileiras. Brasília: Embrapa Informação Tecnológica, 2003. v. 1. (Coleção Espécies Arbóreas Brasileiras).

CARVALHO, P. E. R. Espécies flroestais brasileiras: recomendações silviculturais, 
potencialidades e uso da madeira. São Paulo: Embrapa-CNPF, p. 639, 1994.

CASTELLANI, E. D.; AGUIAR, I. B. Condições preliminares para a germinação de sementes de candiúba (Trema micrantha (L.) Blume.). Rev. bras. eng. agríc. Ambient. v.2, n.1, p.80-83, 1998.

DAVIDE, A. C.; FARIA, J. M. R.; OLIVEIRA, L. M. Quebra de dormência em sementes de candiúva (Trema micrantha (L.) Blume - Ulmaceae). In: CONGRESSO FLORESTAL PANAMERICANO, 1, CONGRESSO FLORESTAL BRASILEIRO, 7, 1993, Curitiba. Anais... São Paulo: Sociedade Brasileira de Silvicultura e Sociedade Brasileira de Engenheiros Florestais, v.2, p. 461-463, 1993.

DUTRA, T. R.; MASSAD, M. D.; SARMENTO, M. F. Q.; OLIVEIRA, J. C. Substratos alternativos e métodos de quebra de dormência para produção de mudas de canafístula. Revista Ceres, v. 60, n. 1, p. 72-78, 2013.

FLORA DO BRASIL 2020 em construção. Jardim Botânico do Rio de Janeiro. Disponível em: < http://floradobrasil.jbrj.gov.br/ > . Acesso em: 11 maio 2017

IBGE - Instituto Brasileiro de Geografia e Estatística. Manual técnico da vegetação brasileira. Rio de Janeiro: IBGE, p. 92, 1993.

KRAMER, P. J.; KOZLOWSKI, T. Fisiologia das árvores. Lisboa: Fundação Calouste Gulbenkian, p. 745, 1972.

LOPEZ, R.R.; LATTUADA, D.S.; FRANKE, L.B. Efeito do período de alagamento na germinação de sementes de Adesmia latifolia (Spreng.) Vog. (Faboideae). In: REUNION DEL GRUPO TÉCNICO REGIONAL DEL CONO SUR EN MEJORAMIENTO Y UTILIZACION DE LOS RECURSOS FORRAJEROS DEL ÁREA TROPICAL Y SUBTROPICAL. Memoria. Salto: Grupo Campos - Sustentabilidad, desarrollo y conservación de los ecosistemas, 2004. p.136-137.

LORENZI, H. Árvores brasileiras: manual de identificação e cultivo de plantas arbóreas nativas do Brasil. Nova Odessa: Plantarum, p. 382, 1992. 
LORENZI, H.; SOUZA, H. M. de; TORRES, M. A. V.; BACHER, L. B. Árvores exóticas no Brasil: madeiras, ornamentais e aromáticas. Nova Odessa: Instituto Plantarum, p. $173,2003$.

LORENZI, H. Árvores exóticas no Brasil: madeireiras, ornamentais e aromáticas. Nova Odessa, SP: Instituto Plantarum, 2003. p. 368. Disponivel em: < http:// sites.unicentro.br/wp/manejoflorestal/11100-2/> . Acesso em: 10 maio 2017.

MARTINS, S. S.; SILVA, I. C.; BORTOLO, L. de; NEPOMUCENO, A. N. Produção de mudas de espécies florestais nos viveiros do instituto ambiental do Paraná. Maringá: Clichetec, p. 192, 2004.

MAEDA, J. A.; LAGO, A. A. Germinação de sementes de mucuna-preta após tratamentos para superação da impermeabilidade do tegumento. Revista Brasileira de Sementes, v. 8, n. 1, p. 79-84, 1986.

SEGHESE, F.; ISSHIKI, K.; VITTI, A.P. Ecofisiologia da germinação de espécies arbóreas. Série Técnica IPEF, Piracicaba, v.8, n. 25, p. 9-11, 1992.

SIEGEL, S. Estatística Não-paramétrica para as Ciências do Comportamento. São Paulo: McGraw-Hill, 1975.

SOUZA, V.C.; LORENZI, H. Botânica Sistemática: guia ilustrado para a identificação das famílias de Angiospermas da flora brasileira, baseado em APG/II. Nova Odessa: Instituto Plantarum, 2005.

RODRIGUES, E. H. A.; AGUIAR, I. B.; SADER, R. Quebra de dormência de sementes de três espécies do gênero Cassia. Revista Brasileira de Sementes, v. 12, n. 12, p. 17-25, 1990.

TAIZ, L.; ZEIGER, E.; MOLLER, I. A.; MURPHY, A. Fisiologia e desenvolvimento vegetal. 6. ed. Porto Alegre: Artmed, 2017.

VIEIRA, I. G.; FERNADES, G. D. Métodos de quebra de dormência de sementes. IPEF, Piracicaba, n. 27, nov. 1997. Disponível em: < http://www.ipef.br/tecsementes/ dormencia.asp > . Acesso em: 10 maio 2017. 
WEBSTER, C.R.; NELSON, K.; WANGEN, S.R. Stand dynamics of an insular population of an invasive tree, Acer platanoides. Forest Ecology and Management, v. 208, p. 85-99, 2005.

ZILLER, S.R. Plantas exóticas invasoras: a ameaça da contaminação biológica. Ciência Hoje, v. 30, p. 77-79, 2001.

Recebido em: 26/06/2017 Aceito em: 06/07/2017 